\title{
Inclusion of the Ligand Field Contribution in a Polarizable Molecular Mechanics: SIBFA-LF
}

\author{
JEAN-PHILIP PIQUEMAL, ${ }^{1}$ BEN WILLIAMS-HUBBARD, ${ }^{2}$ NATALIE FEY, ${ }^{2}$ ROBERT J. DEETH, ${ }^{2}$ \\ NOHAD GRESH, ${ }^{3}$ CLAUDE GIESSNER-PRETTRE ${ }^{1}$ \\ ${ }^{1}$ Laboratoire de Chimie Théorique, UMR 7616, Université P. \& M. Curie, Case Courrier 137, 4, \\ place Jussieu, 75252 Paris, Cedex 05, France \\ ${ }^{2}$ Department of Chemistry, Inorganic Computational Chemistry Group, University of Warwick, \\ Coventry CV4 7AL, UK \\ ${ }^{3}$ Laboratoire de Pharmacochimie Moléculaire, FRE 2463, U266, Université René Descartes, 4, \\ avenue de l'Observatoire, 75270 Paris, Cedex 06, France
}

Received 22 May 2003; Accepted 4 July 2003

\begin{abstract}
To account for the distortion of the coordination sphere that takes place in complexes containing open-shell metal cations such as $\mathrm{Cu}(\mathrm{II})$, we implemented, in sum of interactions between fragments ab initio computed (SIBFA) molecular mechanics, an additional contribution to take into account the ligand field splitting of the metal $d$ orbitals. This term, based on the angular overlap model, has been parameterized for $\mathrm{Cu}(\mathrm{II})$ coordinated to oxygen and nitrogen ligands. The comparison of the results obtained from density functional theory computations on the one hand and SIBFA or SIBFA-LF on the other shows that SIBFA-LF gives geometric arrangements similar to those obtained from quantum mechanical computations. Moreover, the geometric improvement takes place without downgrading the energetic agreement obtained from SIBFA. The systems considered are $\mathrm{Cu}$ (II) interacting with six water molecules, four ammonia or four imidazoles, and four water plus two formate anions.
\end{abstract}

(ㄷ) 2003 Wiley Periodicals, Inc. J Comput Chem 24: 1963-1970, 2003

Key words: intermolecular interaction; polarizable molecular mechanics; ligand field; $\mathrm{Cu}(\mathrm{II})$

\section{Introduction}

Molecular mechanics is a powerful tool to determine the most stable geometric arrangement of a wide variety of systems provided that the appropriate force field is used. ${ }^{1}$ The development, in the past few years, of polarizable systematics ${ }^{2}$ has promoted the extension of the application field of these methods to systems containing closed-shell metal cations. ${ }^{3-5}$ For such systems these methods are able to provide not only the correct geometric arrangements but also interaction energy values that are in reasonable agreement with the corresponding ab initio quantum mechanical results. ${ }^{4,5}$

Thus, with sum of interactions between fragments $a b$ initio computed molecular mechanics (SIBFA) the total energy is computed as a sum of five terms, calibrated on model monoligated complexes to reproduce their counterparts from $a b$ initio energy decomposition procedures. It was subsequently shown to accurately reproduce the results of $a b$ initio Hartree-Fock (HF) and MP2 computations performed in parallel on polycoordinated complexes of divalent cations and account for the nonadditive character of both second-order terms of the HF interaction energy, polarization and charge-transfer contributions. ${ }^{4}$ It was recently extended to study complexes of inhibitors to a binuclear $\mathrm{Zn}$ metalloenzyme, $\beta$-lactamase. ${ }^{6}$ Until recently, however, the SIBFA formulation/parameterization was limited to closed-shell divalent cations, $\mathrm{Mg}(\mathrm{II}), \mathrm{Ca}(\mathrm{II}), \mathrm{Zn}(\mathrm{II})$, and $\mathrm{Cd}(\mathrm{II}),{ }^{7}$ and to a closed-shell monovalent cation, $\mathrm{Cu}(\mathrm{I}),{ }^{4 \mathrm{c}}$ which is isoelectronic to $\mathrm{Zn}(\mathrm{II})$.

However, when a metal with a partially filled $d$ shell is present in the assembly studied additional "potentials/contributions" have to be included to take into account the ligand field splitting of the $d$ orbitals. There are two types of methods to handle these important electronic contributions, which are responsible for some particular arrangements of the ligands around such metals. The first is to use parameters that depend not only on the metal oxidation state but also on the number of its ligands as well as their spatial arrangement. ${ }^{8}$ The second is to resort to the angular overlap model (AOM). ${ }^{9}$ This procedure appears in particular appropriate when

\footnotetext{
Correspondence to: C. Giessner-Prettre; e-mail: cgp@1ct.jussieu.fr This article includes Supplementary Material available from the authors upon request or via the Internet at ftp://ftp.wiley.com/public/journals/ jcc/suppmat/24/1963 or http://www.interscience.wiley.com/jpages/ 0192-8651/suppmat/24/v24.1963.html
} 
dealing with noncovalent metal cation-ligand interactions as encountered in metalloproteins and enzymes. This type of contribution has been introduced according to two different ways. One has been proposed within an analytic formalism that uses "empirical"10 or "semiclassical"11 procedures. The second proceeds through the diagonalization of an effective $d$ - $d$ Hamiltonian. Then, the ligand field contribution to the energy is given by the sum of the occupied eigenvalues of this Hamiltonian. ${ }^{12-14}$ Such treatments have provided for $\mathrm{Cu}(\mathrm{II}),{ }^{12,15} \mathrm{Ni}(\mathrm{II}), \mathrm{Mn}(\mathrm{II})$, and $\mathrm{Co}(\mathrm{III})$ complexes, geometric arrangements in good agreement with the experimental structures.

Because some of us became recently interested in the extension of polarizable molecular mechanics to complexes containing $\mathrm{Cu}$ (II) cation, ${ }^{16}$ we found necessary to refine its representation by SIBFA because this systematic, in its actual formulation, was not able to give the Jahn-Teller geometric characteristics exhibited by systems such as $\mathrm{Cu}(\mathrm{II})-\left(\mathrm{H}_{2} \mathrm{O}\right)_{6}$ or $\mathrm{Cu}(\mathrm{II})-\left(\mathrm{NH}_{3}\right)_{4}$. Because of the importance of the ligand-ligand interactions in the overall complex energetics it is desirable to have a systematic able to give both correct ligand-ligand and metal-ligand distances. To reach that objective we chose to retain the SIBFA energetic scheme with an additional ligand field contribution with only minimal modifications of the $\mathrm{Cu}$ (II)-specific energy parameters. This additional energy term is based on the AOM previously demonstrated to be well appropriate for complexes of open-shell cations. ${ }^{12 \mathrm{~b}}$

The parameterization is carried out on a series of monoligated $\mathrm{Cu}$ (II) complexes with representative neutral and anionic ligands. The latter include the formamidate anion, which results from $\mathrm{Cu}$ (II)-induced deprotonation of the amide linkage in some peptides and proteins, following $\mathrm{Cu}$ (II) binding. ${ }^{17 \mathrm{a}-17 \mathrm{~d}}$ This anion is also encountered in the structure of $\mathrm{Cu}$ (II) complexes of triaminodiamido ligands having anti-inflammatory potencies. ${ }^{17 \mathrm{~d}}$ The parameterization is done by comparison with $a b$ initio HF computations in which the interaction energy is deconvoluted into its individual components using constrained space orbital variation (CSOV). This will be followed by the study of several polyligated $\mathrm{Cu}$ (II) complexes to determine the extent to which the SIBFA-LF procedure can approach the results of $a b$ initio computations, from both structural and energetic standpoints for such systems. The SIBFA-LF results will also be compared to those from the "standard" SIBFA procedure.

\section{Computational Methods}

In the SIBFA-LF procedure, the interaction energy, $\Delta E_{\text {int }}$, is computed as a sum of six separate terms:

$$
\Delta E_{\mathrm{int}}=E_{\mathrm{MTP}}+E_{\mathrm{rep}}+E_{\mathrm{pol}}+E_{\mathrm{ct}}+E_{\mathrm{disp}}+E_{\mathrm{LFSE}} .
$$

$E_{\mathrm{MTP}}$ is the electrostatic (multipolar) component, computed as a sum of multipole-multipole interaction terms. The multipoles (up to quadrupoles) are distributed on the atoms and bonds of the individual molecules or molecular fragments making up a larger molecule. They are derived from the $a b$ initio HF molecular wave function using the procedure developed by Vigné-Maeder and Claverie. $^{18}$
$E_{\text {rep }}$ is the short-range repulsion energy. To account for its anisotropic character, it is computed as a sum of bond-bond, bond-lone pair, and lone pair-lone pair interactions. The formulation of $E_{\text {rep }}$ takes into account the hybridization of the bonds, in addition to that of the lone pairs. The expression of $E_{\text {rep }}$ was detailed in the general case and for ligand-cation interactions in refs. $4 \mathrm{~d}$ and $7 \mathrm{a}$ respectively. $E_{\mathrm{pol}}$ is the polarization energy component, calculated with distributed anisotropic polarizabilities on the individual molecular fragments. The polarizabilities are distributed on the centroids of the localized orbitals (heteroatom lone pairs and bond barycenters) using the procedure of Garmer and Stevens. ${ }^{19}$ A Gaussian screening of the polarizing field is used (see ref. $7 \mathrm{a}$ for details). The fragment multipoles and polarizabilities are derived from $a b$ initio computations using the DZVP2 basis set of Godbout et al. ${ }^{20}$ They were calculated using GAMESS software. ${ }^{21}$

$E_{\mathrm{ct}}$ is the charge-transfer contribution. The numerator of $E_{\mathrm{ct}}$ is a function of the overlap between the lone pair hybrid orbitals of the electron donor and the electron acceptor cation, and the denominator takes into account the difference between the ionization potential $I_{\mathrm{L} \alpha}$ of the electron donor and the electron affinity $A_{\beta^{*}}$ of the electron acceptor. $I_{\mathrm{L} \alpha}$ is increased by the predominantly positive electrostatic potential exerted on this atom by the all the other molecules in the complex, whereas $A_{\beta^{*}}$ is reduced by the predominantly negative electrostatic potential due to its surrounding ligands. The dependency of the denominator upon electrostatic potential and field effects was found essential to account for the strong nonadditive character of $E_{\mathrm{ct}}$ in polyligated $\mathrm{Zn}$ (II) complexes. The detailed expression for $E_{\mathrm{ct}}$ can be found in ref. 7a.

$E_{\text {disp }}$ is the dispersion component, which follows the formulation of Creuzet et al. ${ }^{22}$ and is expressed as a sum of $1 / R,{ }^{6} 1 / R,{ }^{8}$ and $1 / R^{10}$ terms, each of which is reduced by an exponential damping term. $E_{\text {disp }}$ includes an exchange-dispersion contribution, $E_{\text {exch }}{ }^{-1 i s p}$. Directionality effects are accounted for by the explicit introduction of fictitious atoms, with reduced van der Waals radii, to represent the lone pairs. These terms were formulated and calibrated to reproduce the radial behavior of $E_{\text {disp }}$ computed by symmetry-adapted perturbation theory ${ }^{23}$ computations on the water dimer.

To treat transition metals with partially filled $d$ orbitals, a new contribution to SIBFA's total intermolecular energy based on the AOM has been added. In the case of open shell cations, JahnTeller ${ }^{24}$ distortion can take place. Such distortions are due to ligand field (LF) effects responsible for the splitting of the metal d orbital energies. A $b$ initio computations are able to account for such geometric arrangements. ${ }^{25}$ In the case of an intermolecular energetic scheme, the LF contribution can be seen as a perturbation of the metal's $d$ orbitals by the ligands. The addition of an AOM term has been shown to handle properly the $d$ orbital splitting due to ligand field ${ }^{12,15}$ when other contributions such as electrostatics fail. ${ }^{9}$ Such a procedure can be considered a simplification of a molecular orbital treatment of the metal $d$ orbitals plus those located on the ligands that are involved in metal coordination. Moreover, it is able to generate the nonspherical potential necessary to handle metal-ligand interactions and allows the treatment of several "chemical effects" such as $\sigma$ or $\pi$ bonding and $s d$ mixing. The present work is limited to the $\sigma$ bonding contribution even if $\pi$ bonding and $s d$ mixing can be handled by the code. 
Table 1. Angular Coefficients Between the Different $d$ Orbitals and Ligand $\sigma$ Bonding Orbital.

\begin{tabular}{ll}
\hline$i$ & \multicolumn{1}{c}{$D i(\theta i, \phi i)$} \\
\hline$z^{2}$ & $1 / 2\left(3 \cos ^{2} \theta-1\right)$ \\
$y z$ & $1 / 2(\sqrt{ } 3 \sin 2 \theta \sin \phi)$ \\
$x z$ & $1 / 2(\sqrt{ } 3 \sin 2 \theta \sin \phi)$ \\
$x y$ & $1 / 4(\sqrt{ } 3(1-\cos 2 \theta) \sin 2 \phi)$ \\
$x^{2}-y^{2}$ & $1 / 4(\sqrt{ } 3(1-\cos 2 \theta) \cos 2 \phi)$ \\
\hline
\end{tabular}

AOM is based on the fact that the relative energy change of the metal $d$ orbitals, due to the ligand field, can be related to their overlap with the ligand orbitals. ${ }^{26}$ These overlap integrals can be factored into a radial and an angular part. The radial part of the overlap can be considered as a constant for a fixed internuclear distance and can be parameterized for a given metal-ligand pair. The angular part, which depends on the relative orientation of the metal $d$ orbitals with respect to those of the ligands, is the main term that has to be calculated. So, with AOM treatment a simplified effective Hamiltonian is built on the basis of the $d$ orbitals. Its evaluation, made using spherical coordinates $(\theta, \phi)$, gives an energy matrix that has to be diagonalized.

In the present calculation, each ligand is considered separately and the total matrix reflects the sum of the local perturbation of the metal's $d$ orbitals by the ligands; so, each matrix element is the sum of all the contributions from each ligand. The matrix is constructed using angular coefficients $D_{i}$, reported in Table 1 , which give the angular overlap values for a ligand $\sigma$ orbital.

In addition to the angular part, the radial contribution of each ligand to the total overlap with the metal has to be introduced into an $e_{\lambda}$ parameter in which is included the energetics of the $\sigma$ (or $\pi$, neglected in the present work) bonding. Following Woodley et al., ${ }^{14}$ we used an exponential decay of the radial part of the overlap:

$$
e_{\lambda}=a+b \exp (-\alpha \cdot r)
$$

where $r$ is the metal-ligand distance and $a, b$, and $\alpha$ are parameters that are different for each type of metal-ligand couple (given in the supplementary materials). Such a choice is necessary to allow geometry optimization. The matrix elements take the form

$$
\mathscr{H}_{d d^{\prime}}=\sum_{l} e_{\lambda}^{l}\langle d \mid l\rangle\left\langle l \mid d^{\prime}\right\rangle
$$

the summation running over the orbitals of the heteroatoms that belong to the ligands.

The eigenvalues of this matrix provide the relative energy levels of the $d$ orbitals that are necessary to compute the LF contribution to SIBFA, noted $E_{\text {lfse }}$. So, for a $d^{n}$ system

$$
E_{\mathrm{LFSE}}=-2 \sum_{i=1}^{5} \varepsilon_{i}+\sum_{i=1}^{n} \rho_{i} \varepsilon_{i}+E_{\mathrm{wall}}
$$

where the $\varepsilon_{i}$ are the energies of the $d$ orbitals and $\rho_{i}$ their occupation number $(0,1,2)$.

Because of the short distance nature of the AOM-based ligand field energy, $E_{\text {wall, }}$ which is a repulsive force coupled to AOM energy, is necessary to avoid a possible collapse of the ligands on the metal during the optimizations as well as for a better agreement of the total intermolecular energy. We use

$$
E_{\text {wall }}=\sum_{l} c_{\mathrm{mul}} \cdot \exp (-\gamma \cdot r)
$$

where $c_{\text {mul }}$ and $\gamma$ are, as in the case of $e_{\lambda}$, parameters for a given metal-ligand couple and $r$ the metal-ligand distance. The parameters actually used in this work are given in the supplementary materials.

The quantum mechanical computations carried out as benchmarks for the SIBFA-LF results were carried out with the DZVP2 basis set ${ }^{20}$ using Gaussian $98 .{ }^{27}$ The CSOV $^{28}$ intermolecular interaction energy decompositions were carried out with a modified version ${ }^{29}$ of HONDO95.3. ${ }^{30}$ SIBFA energy-minimizations were done with the polyvalent Merlin package. ${ }^{31}$ This package can use in succession, following a user-defined order, both gradient-based and nongradient-based minimizers. At present, the gradients are computed numerically. Expressions for the analytic first-order derivatives of the energy, aside from the already implemented $E_{\mathrm{MTP}}$ ones, are at present being introduced in the code.

In Tables 1 and 2, we compare the results of SIBFA-LF and of SIBFA devoid of the LF contribution to their quantum chemical (QC) counterparts. In these tables $E_{\mathrm{es}}$ and $E_{\mathrm{MTP}}$ denote, respectively, the QC Coulomb and the SIBFA electrostatic (multipolar) components of the interaction energy; $E_{\text {ex }}$ and $E_{\text {rep }}$ denote similarly the QC exchange and SIBFA short-range repulsion components; $E_{1}$ is the sum of $E_{\mathrm{es}}$ and $E_{\mathrm{ex}}(\mathrm{QC})$ and of $E_{\mathrm{MTP}}$ and $E_{\mathrm{rep}}$ (SIBFA). Recall that because at present $E_{\mathrm{MTP}}$ is devoid of an actual penetration term, ${ }^{32}$ as in ref. $7 \mathrm{a}, E_{\text {rep }}$ was calibrated so that the sum of $E_{\mathrm{MTP}}$ and $E_{\text {rep }}$, namely, $E_{1}$, matches $E_{1}(\mathrm{QC})$.

$E_{\mathrm{pol}}$ and $E_{\mathrm{ct}}$ are the polarization and charge-transfer components from both QC and SIBFA approaches, the subscripts $M$ or $L$ denoting the cation and ligands, respectively. $E_{2}$ is the sum of $E_{\text {pol }}$ and $E_{\mathrm{ct}} \cdot E_{\mathrm{clfse}}$ denotes the LF contribution in the SIBFA-LF approach. We denote by $\Delta E$ (without subscript), respectively, the $\mathrm{HF}$ interaction energy in the QC computations and the SIBFA interaction energy prior to the inclusion of the dispersion energy component. $E_{\text {cor }}$ denotes the QC interaction energy gain upon passing from the HF to the MP2 level, and $E_{\text {disp }}$ denotes the SIBFA dispersion energy component. Finally, $\Delta E_{\text {int }}$ denotes the total interaction energies after adding $E_{\mathrm{cor} / \mathrm{disp}}$ to $\Delta E$.

Because the QC origin of a clfse term cannot be singled out to a uniquely defined component of $\Delta E / \Delta E_{\mathrm{int}}$ that would be obtained from an intermolecular interaction energy analysis, we attempted to account for part of it by rescaling the SIBFA $E_{\text {rep }}, E_{\mathrm{ct}}$, and $E_{\mathrm{disp}}$ parameters concerning $\mathrm{Cu}$ (II) by factors of $1.05,0.22$, and 0.65 , respectively. To reproduce the values of the QC interaction energies at equilibrium distances we calibrated a distinct set of clfse parameters for the different categories of atoms of interest, namely, the $s p,{ }^{3} s p,{ }^{2}$ and carboxylate oxygen atoms, and the $s p^{3}$ as 
Table 2. Values (kcal/mol) of the Intermolecular Interaction Energies and Their Components in Complexes of $\mathrm{Cu}$ (II) with Neutral and Anionic O-Containing Ligands for the $\mathrm{Cu}(\mathrm{II})$ - Ligand Distance $(\AA)$ Optimized at the MP2 Level.

\begin{tabular}{|c|c|c|c|c|c|c|c|c|c|c|c|c|}
\hline \multirow[b]{3}{*}{ Ligand } & \multirow{2}{*}{\multicolumn{3}{|c|}{$\mathrm{H}_{2} \mathrm{O}$}} & \multirow{2}{*}{\multicolumn{3}{|c|}{$\mathrm{HCONH}_{2}$}} & \multicolumn{6}{|c|}{$\mathrm{HCOO}^{-}$} \\
\hline & & & & & & & \multicolumn{3}{|c|}{ Monodentate } & \multicolumn{3}{|c|}{ Bidentate } \\
\hline & $A b$ initio & SIBFA & SIBFA-LF & $A b$ initio & SIBFA & SIBFA-LF & $A b$ initio & SIBFA & SIBFA-LF & Ab initio & SIBFA & SIBFA-LF \\
\hline$E_{\mathrm{es} / \mathrm{MTP}}$ & -93.0 & -73.1 & -73.1 & -128.7 & -94.3 & -94.3 & -359.5 & -318.8 & -318.8 & -381.0 & -341.9 & -341.9 \\
\hline$E_{\text {ex/rep }}$ & 50.8 & 25.8 & 27.1 & 62.9 & 30.1 & 31.6 & 118.1 & 75.6 & 79.4 & 89.8 & 52.6 & 55.2 \\
\hline$E_{1}$ & -42.2 & -47.3 & -46.0 & -65.7 & -64.2 & -62.8 & -241.4 & -243.2 & -239.4 & -291.2 & -289.3 & -286.7 \\
\hline$E_{\mathrm{pol}(\mathrm{M})}$ & -1.8 & -0.8 & -0.8 & -1.6 & -1.2 & -1.2 & -6.0 & -5.7 & -5.7 & -3.6 & -2.7 & -2.7 \\
\hline$E_{\mathrm{ct}(\mathrm{M})}$ & -0.8 & & & -1.3 & & & -1.7 & & & -1.5 & & \\
\hline$E_{\mathrm{pol}(\mathrm{L})}$ & -25.7 & -27 & -27 & -65.3 & -64.5 & -64.5 & -72.0 & -75.1 & -75.1 & -66.5 & -62.2 & -62.2 \\
\hline$E_{\mathrm{ct}(\mathrm{L})}$ & -6.3 & -7.8 & -1.7 & -6.3 & -7.5 & -1.7 & -10.8 & -11.8 & -4.2 & -17.8 & -23.3 & -5.2 \\
\hline$E_{\text {clfse }}$ & & & -12.2 & & & -11.9 & & & -13.6 & & & -32.6 \\
\hline$E_{2}$ & -34.4 & -35.6 & -41.7 & -76.2 & -73.2 & -79.3 & -93.2 & -92.6 & -98.6 & -89.9 & -88.2 & -102.7 \\
\hline$\Delta E$ & -80.5 & -82.9 & -87.7 & -143.9 & -137.4 & -142.2 & -337.9 & -335.8 & -337.8 & -385.4 & -377.5 & -389.4 \\
\hline$E_{\text {cor/disp }}$ & -2.7 & -4.8 & -3.1 & -2.9 & -6.9 & -4.5 & -14.0 & -15.7 & -7.3 & -13.5 & -14.4 & -7.1 \\
\hline$\Delta E_{\text {int }}$ & -83.2 & -87.7 & -90.8 & -146.8 & -144.4 & -146.6 & -351.9 & -351.5 & -345.2 & -398.9 & -391.9 & -396.5 \\
\hline$d(\AA)$ & & 1.9 & & & 1.8 & & & 1.7 & & & 2.0 & \\
\hline$\Delta E_{\mathrm{tot}}^{\mathrm{a}}$ & & & & & -147.2 & & & & & & & \\
\hline$d(\AA)^{\mathrm{b}}$ & & & & & 1.7 & & & & & & & \\
\hline
\end{tabular}

${ }^{\mathrm{a}}$ Value obtained for the SIBFA-optimized distance when different from $a b$ initio.

${ }^{\mathrm{b}}$ SIBFA-optimized distance.

well as $s p^{2}$ nitrogens. This is consistent with the use by SIBFA of different effective van der Waals radii for these types of atoms to compute the individual components of $\Delta E / \Delta E_{\mathrm{tot}}{ }^{7 \mathrm{a}}$

\section{Results and Discussion}

Table 2 reports the results for monoligated complexes of $\mathrm{Cu}$ (II) with representative neutral and anionic O-containing ligands, namely, wa- ter, formamide, and the formate anion. Table 3 reports similar comparisons with $\mathrm{N}$-containing ligands, namely, ammonia, imidazole, pyridine, and the formamidate anion. Table 4 reports the results of calculations bearing on representative polyligated $\mathrm{Cu}(\mathrm{II})$ complexes prone to adopt distinct competing structures, whose relative stabilities could be affected differently by ligand field effects. For the present evaluation we thus investigated: (1) the complexes of $\mathrm{Cu}$ (II) with six water molecules, differing in the number of first-shell coordinating molecules, namely, six, five, and four, the latter two having one and

Table 3. Values (kcal/mol) of the Intermolecular Interaction Energies and Their Components in Complexes of $\mathrm{Cu}$ (II) with Neutral N-Containing Ligands for the $\mathrm{Cu}(\mathrm{II})$ - Ligand Distance ( $\mathrm{A}$ ) Optimized at the MP2 Level.

\begin{tabular}{|c|c|c|c|c|c|c|c|c|c|c|c|c|}
\hline \multirow[b]{2}{*}{ Ligand } & \multicolumn{3}{|c|}{$\mathrm{NH}_{3}$} & \multicolumn{3}{|c|}{$\operatorname{ImH}$} & \multicolumn{3}{|c|}{ Pyridine } & \multicolumn{3}{|c|}{ Formamidate anion } \\
\hline & $A b$ initio & SIBFA & SIBFA-LF & $A b$ initio & SIBFA & SIBFA-LF & $A b$ initio & SIBFA & SIBFA-LF & $A b$ initio & SIBFA & SIBFA-LF \\
\hline$E_{\mathrm{es} / \mathrm{MTP}}$ & -150.5 & -105.7 & -105.7 & -140.4 & -106.7 & -106.7 & -131.3 & -95.0 & -95.0 & -390.0 & -335.5 & -335.5 \\
\hline$E_{\text {ex/rep }}$ & 102.7 & 54.1 & 56.8 & 78.0 & 41.5 & 43.6 & 83.9 & 42.0 & 44.3 & 136.0 & 83.7 & 87.8 \\
\hline$E_{1}$ & -47.8 & -51.6 & -48.9 & -62.4 & -65.1 & -63.1 & -47.4 & -53.0 & -50.7 & -254.0 & -251.8 & -247.8 \\
\hline$E_{\mathrm{pol}(\mathrm{M})}$ & -3.0 & -2.7 & -2.7 & -3.7 & -2.8 & -2.8 & -4.0 & -2.9 & -2.9 & -5.6 & -8.4 & -8.4 \\
\hline$E_{\mathrm{ct}(\mathrm{M})}$ & -1.0 & & & -1.2 & & & -1.2 & & & -1.5 & 0. & 0. \\
\hline $\begin{array}{c}E_{\mathrm{pol}(\mathrm{L})} \\
-80.1\end{array}$ & -41.7 & -41.4 & -41.4 & -76.3 & -79.3 & -79.3 & -81.2 & -81.9 & -81.9 & -74.2 & -80.1 & \\
\hline$E_{\mathrm{ct}(\mathrm{L})}$ & -14.7 & -16.1 & -3.6 & -7.1 & -13.9 & -3.1 & -9.6 & -13.8 & -3.1 & -12.9 & -12.5 & -2.8 \\
\hline$E_{\text {clfse }}$ & & & -17.8 & & & -16.6 & & & -16.6 & & & -28.8 \\
\hline$E_{2}$ & -62.8 & -60.2 & -65.5 & -88.3 & -95.9 & -99.3 & -98.5 & -98.7 & -104.5 & -98.3 & -101.0 & -120.1 \\
\hline$\Delta E$ & -114.9 & -111.8 & -114.2 & -156.6 & -161.0 & -164.6 & -150.4 & -151.5 & -155.2 & -358.2 & -352.8 & -367.9 \\
\hline$E_{\text {cor } / \text { disp }}$ & -6.1 & -10.2 & -6.6 & -10.6 & -9.5 & -6.2 & -13.0 & -10.2 & -6.6 & -16.4 & -11.0 & -6.6 \\
\hline $\begin{array}{l}\Delta E_{\mathrm{int}} \\
d(\AA)\end{array}$ & -121.0 & $\begin{array}{r}-122.0 \\
1.9\end{array}$ & -120.8 & -167.2 & $\begin{array}{r}-170.3 \\
1.9\end{array}$ & -170.8 & -163.6 & $\begin{array}{r}-161.8 \\
1.9\end{array}$ & -161.8 & -374.6 & $\begin{array}{r}-363.8 \\
1.8\end{array}$ & -374.5 \\
\hline
\end{tabular}


Table 4. Interaction Energies (kcal/mol) and $\mathrm{Cu}$-Ligand Optimized Distances $(\AA)$ in $\mathrm{Cu}(\mathrm{II})$.

\begin{tabular}{|c|c|c|c|c|c|c|c|c|}
\hline \multirow[b]{2}{*}{ Ligands } & \multicolumn{2}{|c|}{ SIBFA-LF } & \multicolumn{2}{|c|}{ SIBFA } & \multicolumn{2}{|c|}{$\mathrm{MP}^{\mathrm{a}}$} & \multicolumn{2}{|c|}{$\mathrm{DFT}^{\mathrm{b}}$} \\
\hline & $\Delta E$ & $d \mathrm{Cu}-\mathrm{L}$ & $\Delta E$ & $d \mathrm{Cu}-\mathrm{L}$ & SIBFA-LF & SIBFA & $\Delta E$ & $d \mathrm{Cu}-\mathrm{L}$ \\
\hline$\left(\mathrm{H}_{2} \mathrm{O}\right)_{6}$ & -340.9 & $1.99 / 2.17$ & -349.4 & 2.06 & -346.4 & -347.1 & $-366.4(-342.4)$ & $2.01 / 2.05 / 2.27$ \\
\hline$\left(\mathrm{H}_{2} \mathrm{O}\right)_{5}-\mathrm{H}_{2} \mathrm{O}$ & -335.8 & $1.98-2.0 / 2.21$ & -340.9 & 1.99 & -343.5 & -342.2 & -373.1 & $2.01 / 2.29$ \\
\hline$\left(\mathrm{H}_{2} \mathrm{O}\right)_{4}-\left(\mathrm{H}_{2} \mathrm{O}\right)_{2}$ & -334.7 & $1.98 / 1.99$ & -331.5 & $1.97 / 1.99$ & -339.6 & -334.2 & -378.9 & \\
\hline$\left(\mathrm{NH}_{3}\right)_{4}$ & -328.9 & 2.11 & -300.1 & 2.09 & -328.7 & -325.9 & -380.1 & 2.07 \\
\hline$\left(\mathrm{NH}_{3}\right)_{6}$ & -384.7 & $2.18 / 2.39$ & -386.7 & 2.23 & -383.9 & -390.3 & -419.0 & $2.10 / 2.68$ \\
\hline$(\operatorname{ImH})_{4}$ & -427.4 & $2.03 / 2.04$ & -429.4 & $2.03 / 2.04$ & -434.0 & -417.9 & $-453.1(-434.2)$ & 2.02 \\
\hline$\left(\mathrm{HCOO}^{-}\right)_{2}\left(\mathrm{H}_{2} \mathrm{O}\right)_{4}{ }^{\mathrm{c}}$ & -713.0 & & -700.2 & & -705.0 & -704.2 & $-711.0(-709.9)$ & \\
\hline $\mathrm{HCOO}^{-}\left(\mathrm{H}_{2} \mathrm{O}\right)_{4} \mathrm{HCOO}^{\mathrm{d}}$ & -695.3 & & -686.2 & & -690.2 & -689.2 & $-711.9(-704.9)$ & \\
\hline
\end{tabular}

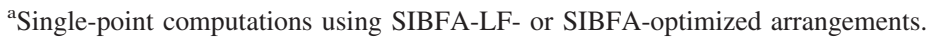

${ }^{\mathrm{b}}$ Fully optimized geometry. Values in parentheses correspond to MP2 results obtained for the DFT-optimized geometries.

cDepicted in Fig. 3(A).

${ }^{\mathrm{d}}$ Depicted in Fig. 3(B).

two outer-shell waters, respectively; (2) the complexes of $\mathrm{Cu}$ (II) with four and six ammonia ligands as well as with four imidazole ligands; (3) the complexes of $\mathrm{Cu}(\mathrm{II})$ with two formate anions and four water molecules, in which one formate interacts in either a direct, or in a through-water binding mode, with $\mathrm{Cu}(\mathrm{II})$.

\section{Monoligated Complexes}

The values reported in Tables 2 and 3 show that SIBFA-LF is able to provide a match to $\Delta E_{\text {tot }}(\mathrm{QC})$ comparable to that obtained from SIBFA. For oxygen-containing ligands, the $\mathrm{Cu}(\mathrm{II})-\mathrm{H}_{2} \mathrm{O}$ complex is the only one for which SIBFA-LF overestimates $\Delta E_{\text {int }}$ with respect to $\Delta E_{\text {int }}(\mathrm{QC})$. This overestimation amounting to $7.8 \mathrm{kcal} /$ mol was already present in SIBFA prior to LF introduction, then amounting to $4.6 \mathrm{kcal} / \mathrm{mol}$. Note that to our knowledge, with the exception of an earlier study devoted to manganese oxides, ${ }^{14}$ none of the previous developments of AOM or clfse systematics have dealt so far with oxygen ligands. Further, in the case of the $\mathrm{Cu}$ (II) complexes with formamide and formate an actual improvement of the reproduction of $\Delta E_{\mathrm{int}}(\mathrm{QC})$ is observed compared to the previous SIBFA results. For $s p^{3}$ nitrogens, as in ammonia, SIBFA-LF leads to a decrease of $\Delta E_{\text {int }}$ absolute value that is not significant $(1.2 \mathrm{kcal} / \mathrm{mol}$ of 120$)$. For both $s p^{2} \mathrm{~N}$-containing ligands, imidazole and pyridine, SIBFA and SIBFA-LF give the same difference with QC results. In the case of the formamidate anion SIBFA-LF results are in excellent agreement with the QC values while SIBFA underestimates the interaction energy by more than $10 \mathrm{kcal} / \mathrm{mol}$.

\section{Polyligated Complexes}

The polyligated complexes should provide a critical test for the capability of an explicit clfse term to account for the energetic and structural features of these complexes, as observed from either high-level $a b$ initio computations or high-resolution structural studies. The corresponding results are reported in Table 4.

\section{Complexes of $\mathrm{Cu}(\mathrm{II})$ with Six Water Molecules}

For the three complexes investigated, single-point MP2 computations were done at the minima that were obtained from both SIBFA-LF and SIBFA approaches. Both molecular mechanics computations provide the energy ordering: $\left(\mathrm{H}_{2} \mathrm{O}\right)_{6}>\left(\mathrm{H}_{2} \mathrm{O}\right)_{5}-$ $\mathrm{H}_{2} \mathrm{O}>\left(\mathrm{H}_{2} \mathrm{O}\right)_{4}-\left(\mathrm{H}_{2} \mathrm{O}\right)_{2}$. The latter two complexes have, respectively, five inner-shell waters and one outer-shell one and four inner-shell waters and two outer-shell ones. The MP2 computations have the same ordering as SIBFA, thus favoring six, over five and four, inner-shell $\mathrm{Cu}(\mathrm{II})$-coordinating water molecules. While for the $\mathrm{Cu}(\mathrm{II})-\left(\mathrm{H}_{2} \mathrm{O}\right)_{6}$ at the outcome of minimization SIBFA leads to six equal $\mathrm{Cu}(\mathrm{II})-\mathrm{O}$ distances $(2.06 \AA)$, SIBFA-LF gives an elongation of the axial $\mathrm{Cu}(\mathrm{II})-\mathrm{O}$ distances $(2.17 \AA)$, concomitant with a slight contraction of the four equatorial $\mathrm{Cu}(\mathrm{II})-\mathrm{O}$ ones $(1.99 \AA) . \Delta E_{\text {int }}$ from MP2 has values that are closely similar (within $1 \mathrm{kcal} / \mathrm{mol}$ of 347) for the two SIBFA geometries. Similarly, for the $\mathrm{Cu}(\mathrm{II})-\left(\mathrm{H}_{2} \mathrm{O}\right)_{5}\left(\mathrm{H}_{2} \mathrm{O}\right)$ complex five equal $\mathrm{Cu}(\mathrm{II})-\mathrm{O}$ distances $(1.99 \AA)$ are obtained from SIBFA, while an elongated axial $\mathrm{Cu}(\mathrm{II})-\mathrm{O}$ distance $(2.21 \AA)$ is found when resorting to SIBFA-LF. Again, $\Delta E_{\text {int }}$ from MP2 has closely similar values when using the SIBFA-LF and SIBFA geometries, slightly favoring the former one. An instructive illustration of the improvement brought about by clfse is provided by the $\mathrm{Cu}(\mathrm{II})-\left(\mathrm{H}_{2} \mathrm{O}\right)_{4}\left(\mathrm{H}_{2} \mathrm{O}\right)_{2}$ complex. SIBFA energy minimization converges into a tetrahedral arrangement centred around $\mathrm{Cu}(\mathrm{II})$, displayed in Figure 1(A), which is consistent with the previous results obtained for the closed-shell $\mathrm{Zn}(\mathrm{II})^{4 \mathrm{a}}$ and $\mathrm{Cu}(\mathrm{I})^{4 \mathrm{~b}}$ tetrahydrates. By contrast, SIBFA-LF energy minimization converges into the four innershell waters in a planar arrangement around $\mathrm{Cu}(\mathrm{II})$ displayed in Figure 1(B). In this arrangement, one inner-shell water, $\mathrm{W}_{1}$, acts as a hydrogen bond donor to the two outer-shell waters, each of which acts as an additional $\mathrm{H}$ bond acceptor from an inner-shell water cis to $\mathrm{W}_{1}$. Single-point MP2 computations have a $5-\mathrm{kcal} / \mathrm{mol}$ preference in favor of the planar arrangement. This structural preference is thus consistent with the SIBFA-LF results. This is encouraging considering that no recalibration of clfse was done 

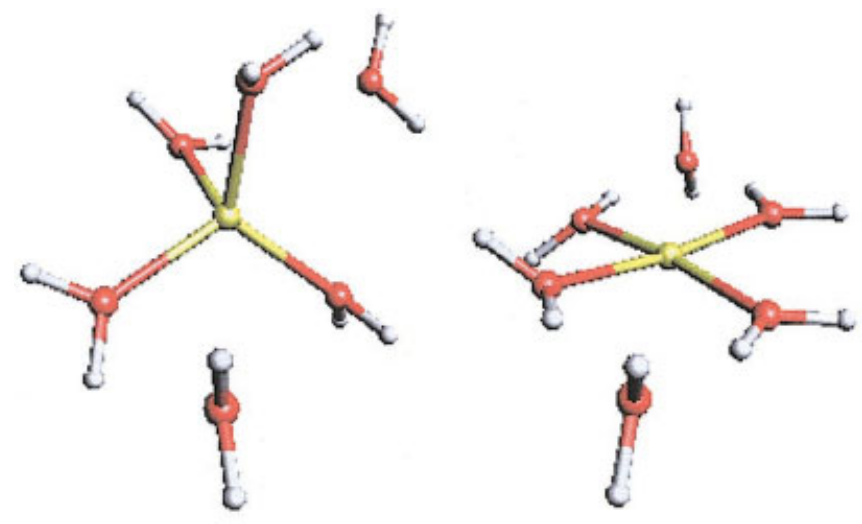

A

SIBFA

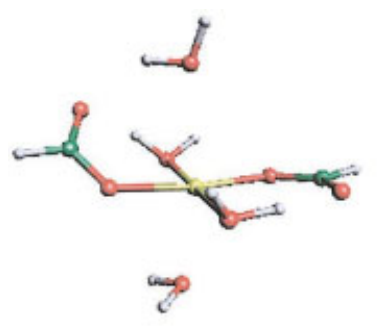

A

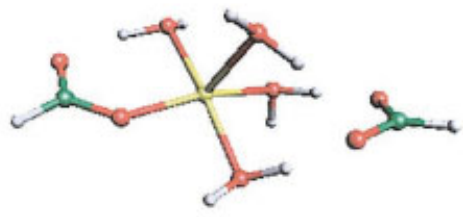

B

Figure 3.

$\mathrm{Cu}(\mathrm{II})-\left(\mathrm{H}_{2} \mathrm{O}\right)_{4}\left(\mathrm{H}_{2} \mathrm{O}\right)_{2}$ more stable than $\mathrm{Cu}(\mathrm{II})-\left(\mathrm{H}_{2} \mathrm{O}\right)_{6}$ and binding energies significantly $(20 \mathrm{kcal} / \mathrm{mol})$ stronger than the MP2 ones. The extent of Jahn-Teller deformation is also more pronounced, the elongation of the two axial $\mathrm{O}-\mathrm{Cu}$ (II) distances being $0.1 \AA$ larger than in SIBFA-LF. In connection with these results, we can recall that recent calculations bearing on the complexes of $\mathrm{Cu}(\mathrm{II})$ with $\mathrm{O}, \mathrm{N}$, and $\mathrm{S}$ ligands $^{33}$ indicated B3LYP to provide energies 20-30 kcal/mol lower than CCSD(T). Present MP2 computations are closer to $\operatorname{CCSD}(\mathrm{T})$ than to B3LYP. A tendency of DFT to favor the $\mathrm{M}(\mathrm{II})-\left(\mathrm{H}_{2} \mathrm{O}\right)_{5}\left(\mathrm{H}_{2} \mathrm{O}\right)$ arrangement over the $\mathrm{M}(\mathrm{II})-\left(\mathrm{H}_{2} \mathrm{O}\right)_{6}$ one was also obtained previously. ${ }^{34}$

\section{Complexes of $\mathrm{Cu}(\mathrm{II})$ with Nitrogen Ligands}

that $\Delta E_{\text {tot }}$ (SIBFA) reproduces single-point $\Delta E_{\text {tot }}(\mathrm{MP} 2)$ at the same geometry to within $3 \mathrm{kcal} / \mathrm{mol}$ of 330 , namely, a relative error of $1 \%$. SIBFA-LF has a somewhat enlarged error with respect to the MP2 computation at the corresponding geometry (5.5-7.8 kcal/mol of 330, namely, a relative error of $2.5 \%$ ). However, the SIBFA-LF approach correctly predicts a square-planar arrangement to be more stable than the tetrahedral one in the case of the $\mathrm{Cu}(\mathrm{II})-\left(\mathrm{H}_{2} \mathrm{O}\right)_{4}\left(\mathrm{H}_{2} \mathrm{O}\right)_{2}$ complex. Note in this respect that the difference of interaction energies between the two extreme complexes, namely, $\mathrm{Cu}(\mathrm{II})-\left(\mathrm{H}_{2} \mathrm{O}\right)_{6}$ and $\mathrm{Cu}(\mathrm{II})-\left(\mathrm{H}_{2} \mathrm{O}\right)_{4}\left(\mathrm{H}_{2} \mathrm{O}\right)_{2}$, is with SIBFA-LF equal to $6.1 \mathrm{kcal} / \mathrm{mol}$, thus much closer to the corresponding MP2 difference of $6.8 \mathrm{kcal} / \mathrm{mol}$ than SIBFA $(17.9 \mathrm{kcal} /$ mol).

At this point we should mention that density functional theory (DFT) energy minimizations give both $\mathrm{Cu}(\mathrm{II})-\left(\mathrm{H}_{2} \mathrm{O}\right)_{5}\left(\mathrm{H}_{2} \mathrm{O}\right)$ and

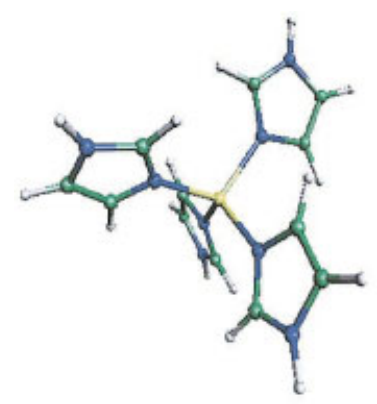

A

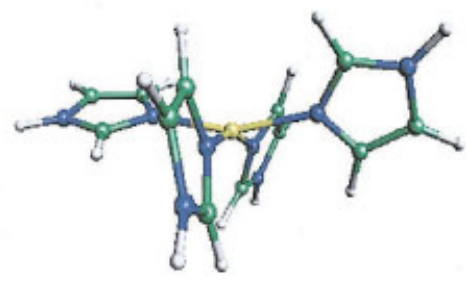

B

SIBFA-LF
In the case of $\mathrm{Cu}(\mathrm{II})-\left(\mathrm{NH}_{3}\right)_{4}$ energy minimization with SIBFA-LF converges into a quasiplanar $\left(D_{2 d}\right)$ arrangement, while using SIBFA leads to a tetrahedral arrangement, similar to the results found, when using this procedure, for water ligands. Single-point MP2 computations confirm the SIBFA-LF results and provide a $2.9-\mathrm{kcal} / \mathrm{mol}$ preference in favor of a $D_{2 d}$ over a $T_{d}$ arrangement. For the quasiplanar one, SIBFA-LF gives the same values of the interaction energy $(-328.9 \mathrm{kcal} / \mathrm{mol})$ as $\Delta E_{\text {int }}(\mathrm{MP} 2)$ at the corresponding geometry. On the other hand, SIBFA underestimates $\Delta E_{\text {int }}(\mathrm{MP} 2)$ in its converged tetrahedral minimum by $25.9 \mathrm{kcal} /$ mol.

In the case of $\mathrm{Cu}(\mathrm{II})-\left(\mathrm{NH}_{3}\right)_{6}$ the energy minimization using SIBFA-LF results in an elongation of the two axial $\mathrm{Cu}(\mathrm{II})-\mathrm{N}$ distances that reach $2.39 \AA$ accompanied by a shortening of the four equatorial $\mathrm{Cu}(\mathrm{II})-\mathrm{N}$ ones to $2.18 \AA$. On the other hand, SIBFA results into all six $\mathrm{Cu}(\mathrm{II})-\mathrm{N}$ distances equalized $(2.23 \AA$ ). DFT energy minimization produces a much more pronounced elongation of the $\mathrm{Cu}(\mathrm{II})-\mathrm{N}$ distances, which become $2.68 \AA$, that is, $0.30 \AA$ larger than from SIBFA-LF, along with shorter in-plane $\mathrm{Cu}(\mathrm{II})-\mathrm{N}$ distances $(2.10 \AA)$. A single-point MP2 computation at the SIBFA-LF geometry gives (within $0.2 \mathrm{kcal} / \mathrm{mol}$ ) an identical interaction energy as SIBFA-LF. The SIBFA geometry, with all $\mathrm{Cu}(\mathrm{II})-\mathrm{N}$ distances equal, provides an actually lower $(3.9 \mathrm{kcal} /$ mol) MP2 interaction energy. This suggests that the best binding $\mathrm{Cu}(\mathrm{II})-\left(\mathrm{NH}_{3}\right)_{6}$ structure in terms of its MP2 interaction could be intermediate between those obtained by SIBFA-LF and DFT.

In the case of $\mathrm{Cu}$ (II) interacting with four imidazoles $(\mathrm{ImH})$, SIBFA-LF energy minimization using a tetrahedral arrangement as a starting point converges into a quasiplanar $D_{2 d}$ arrangement shown in Figure 2(B). In marked contrast, the corresponding 
SIBFA minimization remains, consistent with the previous results obtained with $\mathrm{Cu}(\mathrm{I}),{ }^{4 \mathrm{~b}}$ in a tetrahedral arrangement shown in Figure 2(A). DFT energy minimization converges into a quasiplanar arrangement as SIBFA-LF does. A single-point MP2 computation using the SIBFA-LF geometry yields an identical interaction energy to one performed on the DFT-optimized geometry. Such an interaction energy $(-434.0 \mathrm{kcal} / \mathrm{mol})$ is also more favorable than the $-417.9-\mathrm{kcal} / \mathrm{mol}$ one in the SIBFA-optimized tetrahedral arrangement.

\section{Complexes Simultaneously Involving Anionic and Neutral Ligands}

In view of simulations of $\mathrm{Cu}$ (II) complexes encountered in biologic and biomimetic systems, it was necessary to test SIBFA-LF in complexes in which both anionic and neutral ligands are present. A representative example is provided by complexes made out of two formate anions and four water molecules. Two competing arrangements were energy minimized by SIBFA and SIBFA-LF. In the first, Figure $3(\mathrm{~A}), \mathrm{Cu}$ (II) interacts in a monodentate mode with both formates and all four waters in its first coordination shell. In the second arrangement, Figure 3(B), one formate is in the second shell and binds to $\mathrm{Cu}$ (II) through two water molecules. SIBFA-LF gives rise to a preference favoring A over B by 21 $\mathrm{kcal} / \mathrm{mol}$. Both $E_{\mathrm{pol}}$ and $E_{\mathrm{ct}}$ favor the through-water binding mode, consistent with our previous results on $\mathrm{Zn}$ (II) complexes, ${ }^{4}$ while $E_{1}, E_{\text {disp }}$, and $E_{\text {clfse }}$ favor the direct binding mode. The preference for direct versus through-water binding mode is supported by the MP2 results. Further, SIBFA-LF provides a closer match to $\Delta E_{\text {int }}$ from MP2 than SIBFA. At this point it is worth mentioning that SIBFA-LF gives interaction energies values that are in good agreement with those obtained from MP2 optimizations ( -717.6 and $-696.2 \mathrm{kcal} / \mathrm{mol}$ for the direct and through-water arrangements, respectively).

\section{Conclusion}

Within the context of polarizable molecular mechanics, this article constitutes the first attempt to handle open-shell cations by the inclusion of ligand field stabilization effects. This work was devoted to the $\mathrm{Cu}(\mathrm{II})$ cation, which plays an essential role in numerous biologic and pharmacological processes. We used the AOM formalism to derive an explicit energy contribution that was integrated in the SIBFA procedure along with its five $\Delta E_{\text {int }}$ components. Such an integration was done with only minor recalibrations of the sole $\mathrm{Cu}$ (II) parameters that were originally derived for the $E_{\text {rep }}, E_{\mathrm{ct}}$, and $E_{\text {disp }}$ contributions in the absence of ligand field effects. ${ }^{16}$ It is noted that, except for the newly introduced formamidate nitrogen, all non- $\mathrm{Cu}$ (II) parameters were kept unchanged. An essential asset to calibrate and evaluate the new SIBFA-LF procedure was the availability of high-level QC computations on several mono- and polyligated complexes of $\mathrm{Cu}(\mathrm{II})$. Notably, for polyligated $\mathrm{Cu}$ (II) complexes SIBFA-LF was found to give rise to significantly improved results with respect to SIBFA, which had been formulated in the sole context of closed-shell molecules and cations. Thus, for the representative $\mathrm{Cu}(\mathrm{II})-\left(\mathrm{H}_{2} \mathrm{O}\right)_{6}$ complex SIBFA-LF energy minimization was able to give rise to elongated distances between $\mathrm{Cu}(\mathrm{II})$ and its two axial water molecules. This is fully consistent with the results from DFT and MP2 energy minimizations. By contrast, SIBFA gave rise to six equal $\mathrm{Cu}(\mathrm{II})-\mathrm{O}$ distances, as with a $\mathrm{Zn}(\mathrm{II})-\left(\mathrm{H}_{2} \mathrm{O}\right)_{6}$ complex. For the $\mathrm{Cu}(\mathrm{II})-$ $\left(\mathrm{NH}_{3}\right)_{4}$ and $\mathrm{Cu}(\mathrm{II})-(\mathrm{ImH})_{4}$ complexes, SIBFA-LF energy minimizations converged into quasiplanar $D_{2 d}$ arrangements, consistent with QC energy minimizations, while the SIBFA energy minimizations converged into tetrahedral arrangements, again similar to the corresponding optimized structures obtained with a $\mathrm{Zn}$ (II) cation instead of a $\mathrm{Cu}$ (II) one. We also considered a complex having both anionic and neutral ligands, namely, two formates and four water molecules. SIBFA was able to predict correctly the magnitude of the MP2 energy difference favoring an arrangement with two directly and monodentately bound formates and a $\mathrm{Cu}$ (II) coordination number of six over a competing arrangement with one directly and one through-water bound formate with a $\mathrm{Cu}$ (II) coordination number of five. In all cases investigated, the magnitude of the SIBFA interaction interaction energies, $\Delta E_{\text {int }}$ reproduced consistently the corresponding $\Delta E$ (MP2) with good accuracy, the relative error being $<3 \%$. SIBFA-LF, being basically a molecular mechanics procedure, is considerably faster than any $a b$ initio method. Thus, while a single-point computation on a $\mathrm{Cu}$ (II) hexahydrate took about 1 second CPU time a corresponding full MP2 computation requested about 7 hours. Extension of SIBFA-LF to other open-shell cations could be undertaken by performing related $a b$ initio energy decomposition analyses on their monoligated complexes with representative ligands. The formulation of the $E_{\mathrm{LFSE}}$ contribution enables it to be applied to cations with diverse occupation numbers $\rho(0,1,2)$ of their $d$ orbitals.

These encouraging results suggest that it could be possible to obtain correct geometric arrangements together with reliable energetics using SIBFA-LF method for systems containing openshell metal cations(s) that are too large to be thoroughly studied by quantum mechanical methods.

\section{Acknowledgments}

Computations were carried out at I.D.R.I.S., Orsay, France, C.I.N.E.S., Montpellier, France, and C.C.R., Université P. \& M. Curie, Paris, France.

\section{References}

1. Katritch, V.; Totrov, M.; Abagyan, R. J Comput Chem 2003, 24, 254, and references therein.

2. (a) Halgren, T. A.; Damm, W. Curr Opin Struct Biol 2001, 11, 236; (b) Rein, R.; Claverie, P.; Pollack, M. Int J Quantum Chem 1968, 2, 124; (c) Gresh, N.; Claverie, P.; Pullman, A. Int J Quantum Chem 1986, 29, 101; (d) Bernardo, D. N.; Ding, Y.; Krogh-Jespersen, K.; Levy, R. M. J Phys Chem 1994, 98, 4180;(e) Caldwell, J. W.; Kollman, P. A. J Phys Chem 1995, 99, 6208; (f) Millot, C.; Soetens, J. C.; Martins Costa, N. T. C.; Hodges, M. P.; Stone, A. J. J Phys Chem A 1998, 102, 754; (g) Gordon, M. S.; Freitag, M. A.; Bandyopadhyay, P.; Jensen, J. H.; Kairys, V.; Stevens, W. J. J Phys Chem A 2001, 105, 293; (h) Mannfors, B.; Mirkin, N. G.; Palmo, K.; Krimm, S. J Comput Chem 2001, 22, 1933;(i) Ren, R. J. W. J Comput Chem 2002, 23, 1497; (j) 
Kaminski, G. A.; Stern, H. A.; Berne, B. J.; Friesner, R. A.; Cao, Y. X.; Murphy, R. B.; Zhou, R.; Halgren, T. A. J Comput Chem 2002, 23, 1515; (k) Hermida-Ramón, J. M.; Brdarski, S.; Kärlström, G.; Berg, J. J Comput Chem 2003, 24, 161.

3. (a) Lybrand, T.; Kollman, P. A. J Chem Phys 1985, 83, 2923; (b) Gresh, N. Biochim Biophys Acta 1980, 597, 345.

4. (a) Tiraboschi, G.; Gresh, N.; Giessner-Prettre, C.; Pedersen, L. G.; Deerfield, D. W. J Comput Chem 2000, 21, 1011; (b) Tiraboschi, G.; Roques, B.- P.; Gresh, N. J Comput Chem 1999, 20, 1379; (c) Gresh, N.; Policar, C.; Giessner-Prettre, C; (d) Gresh, N. J Phys Chem A 1997, 101, 8680. J Phys Chem A, 2002, 106, 5660.

5. (a) Sternberg, U.; Koch, F.- T.; Bräuer, M.; Kunert, M.; Anders, E. J Mod Model 2001, 7, 54; (b) Derepas, A.- L.; Soudan, J.- M.; Brenner, V.; Dognon, J.- P.; Millié, P. J Comput Chem 2002, 23, 1013.

6. Antony, J.; Gresh, N.; Hemmingsen, L.; Olsen, L.; Schofield, C.; Bauer, R. J Comput Chem 2002, 23, 1281.

7. (a) Gresh, N. J Comput Chem 1995, 16, 856; (b) Gresh, N.; Garmer, D. R. J Comput Chem 1996, 17, 1481.

8. (a) Boyens, J. C. A.;Comba, P. Coord Chem Rev 2001, 212, 3; (b) Zimmer, M. Chem Rev 1995, 95, 2629; (c) Halgren, T. A. J Comput Chem 1996, 17, 616; (d) Comba, P.; Hambley, T. W. Molecular Modelling of Inorganic Compounds; VCH: Weinheim, Germany, 1995; (e) Comba, P.; Remenyi, R. J Comput Chem 2002, 23, 697, and references therein.

9. (a) Schäffer, C. E.; Jørgensen, C. K. Mol Phys 1964, 9, 401; (b) Gerloch, M.; Harding, J. H.; Wooley, R. G. Struct Bond 1981, 46, 1; (c) Bridgeman, A. J.; Gerloch, M. Progr Inorg Chem 1997, 45, 179.

10. Comba, P.; Hambley, T. W.; Ströhle, M. Helv Chim Acta 1995, 78, 2042.

11. (a) Carlsson, A. E. Phys Rev Lett 1998, 81, 477; (b) Carlsson, A. E.; Zapata, S. Biophys J 2001, 81, 1.

12. (a) Burton, V. J.; Deeth, R. J.; Kemp, C. M.; Gilbert, P. J. J Am Chem Soc 1995, 117, 8407; (b) Deeth, R. J. Coord Chem Rev 2001, 212, 11.

13. (a) Stratemeier, H.; Hitchman, M. A.; Comba, P.; Bernhardt, P. V.; Riley, M. Inorg Chem 1991, 30, 4088; (b) Comba, P.; Hambley, T. W.; Hitchman, M. A.; Stratemeier, H. Inorg Chem 1995, 34, 3903; (c) Schäffer, C. E. Inorg Chim Acta 1995, 240, 581;(d) Schäffer, C. E. Inorg Chim Acta 2000, 300-302, 1035.

14. Woodley, S. M.; Battle, P. D.; Catlow, C. R. A.; Gale, J. D. J Phys Chem B 2001, 105, 6824.

15. (a) Davies, I. W.; Deeth, R. J.; Larsen, R. D.; Reider, P. J. Tetrahedron Lett, 1999, 40, 1233; (b) Deeth, R. J.; Duer, M. J.; Gerloch, M. Inorg Chem 1987, 26, 2573.

16. Ledecq, M.; Lebon, F.; Durant, F.; Giessner-Prettre, C.; Marquez, A.; Gresh, N. J Phys Chem B, 2003, 107, in press.

17. (a) Pushie, M. J.; Rauk, A. J Biol Inorg Chem 2003, 8, 53; (b) Battistuzzi, G.; Borsari, M.; Menabue, L.; Saladini, M. Inorg Chem 1996, 35, 4239; (c) Sigel, H. Chem Rev 1982, 82, 385; (d) Jackson,
G. E.; Mkhonta-Gama, L.; Voyé, A.; Kelly, M. J Inorg Biochem 2000, $79,147$.

18. Vigné-Maeder, F.; Claverie, P. J Chem Phys 1988, 88, 4934.

19. Garmer, D. R.; Stevens, W. J. J Phys Chem 1989, 93, 8263.

20. Godbout, N.; Salahub, D. R.; Andzelm, J.; Wimmer, E. Can J Chem 1992, 70, 560.

21. Schmidt, M. W.; Baldridge, K. K.; Boatz, J. A.; Boatz, S. T.; Elbert, S. T.; Gordon, M. S.; Jensen, J. H.; Koseki, S.; Matsunaga, N.; Nguyen, K. A.; Su, S.; Windus, T. L.; Dupuis, M.; Montgomery, J. A. Jr. J Comput Chem 1993, 14, 1371.

22. Creuzet, S.; Langlet, J.; Gresh, N. J Chim Phys PCB 1991, 88, 2399.

23. Langlet, J.; Caillet, J.; Caffarel, M. J Chem Phys 1995, 103, 8043.

24. (a) Yamatra, H. Acta Chem Scand 1979, A33, 107; (b) Sano, M.; Yamatera, H. Chem Lett 1980, 1495. (c) \&Akessen, R.; Pettersson, L. G. M.; Sandström, M.; Wahlgren, U. J Phys Chem 1992, 96, 150; (d) Brea, M.; Biskupič, S.; Kožǐšek, J. J Mol Struct Theochem 1997, 397, 121.

25. Kundo, T. K.; Bruyndonckx, R.; Daul, C.; Manoharan, P. T. Inorg Chem 1999, 38, 3931.

26. Douglas, B. E.; Hollingsworth, C. A. Symmetry in Bonding and Spectra. An Introduction; Academic Press: Orlando, FL, 1985.

27. Frisch, M. J.; Trucks, G. W.; Schlegel, H. B.; Scuseria, G. E.; Robb, M. A.; Cheeseman, J. R.; Zakrzewski, V. G.; Montgomery, J. A.; Stratmann, R. E.; Burant, J. C.; Dapprich, S.; Millam, J. M.; Daniels, A. D.; Kudin, K. N.; Strain, M. C.; Farkas, O.; Tomasi, J.; Barone, V.; Cossi, M.; Cammi, R.; Mennucci, B.; Pomelli, C.; Adamo, C.; Clifford, F.; Ochterski, J.; Petersson, G. A.; Ayala, P. Y.; Cui, Q.; Morokuma, K.; Malick, D. K.; Rabuck, A. D.; Raghavachari, K.; Foresman, J. B.; Cioslowski, J.; Ortiz, J. V.; Stefanov, B. B.; Liu, G.; Liashenko, A.; Piskorz, P.; Komaromi, I.; Gomperts, R.; Martin, R. L.; Fox, D. J.; Keith, T.; Al-Laham, M. A.; Peng, C. Y.; Nanayakkara, A.; Gonzalez, C.; Challacombe, M.; Gill, P. M. W.; Johnson, B. G.; Chen, W.; Wong, M. W.; Andres, J. L.; Head-Gordon, M.; Replogle E. S.; Pople, J. A. Gaussian 98, revision A7; Gaussian, Inc.: Pittsburgh, PA, 1998.

28. Bagus, P. S.; Hermann, K.; Bauschlicher, C. W. Jr. J Chem Phys 1984, 80, 4378A.

29. Marquez, A. Private communication.

30. Dupuis, M.; Marquez, A.; Davidson, E. R. HONDO 95.3; Quantum Chemistry Program Exchange (QCPE), Indiana University: Bloomington, IN; 1995.

31. Evangelakis, G.; Rizos, J.; Lagaris, I.; Demetropoulos, G. N. Comp Phys Commun 1987, 46, 401.

32. Freitag, M. A.; Gordon, M. S.; Jensen, J. H.; Stevens, W. J. J Chem Phys 2000, 112, 7300

33. El-Nahas, A. M.; Tajima, N.; Hirao, K. Chem Phys Lett 2000, 318, 333.

34. Pavlov, M.; Siegbahn, P. E.; Sandström, M. J Phys Chem A 1998, 102, 219. 